\title{
Aging Behavior of Water-Based YSZ Suspensions for Plasma Spraying of Thermal Barrier Coatings
}

\author{
Maryam Yaghtin $^{1}$ Amirhossein Yaghtin ${ }^{1,2}$ - Pooria Najafisayar ${ }^{3} \cdot$ \\ Zhaolin Tang $^{1,4} \cdot$ Tom Troczynski ${ }^{1}$
}

Submitted: 11 September 2020/in revised form: 22 December 2020/ Accepted: 6 January 2021/Published online: 31 January 2021 (C) ASM International 2021

\begin{abstract}
Suspension stability is a key parameter that should be considered in any coating process utilizing a suspension as the main feedstock. Application of water as the liquid phase for suspension preparation is promising due to its availability, low cost and no toxicity. In the present study, the effects of three surfactants, polyethyleneimine (PEI), 2-phosphonobutane-1,2,4-tricarboxylic acid (PBTCA) and $\alpha$-Terpineol, on the functional stability of yttria-stabilized zirconia (YSZ) water-based suspensions were investigated. The changes in the suspensions' zeta potential, $\mathrm{pH}$, viscosity and Turbiscan Stability Index (TSI) were monitored over their aging time of 1 to 7 days. The results showed that $\alpha$-Terpineol is the most effective surfactant to produce functionally stable suspensions with low viscosity and surface tension values. Plasma spraying of such stable suspensions results in the formation
\end{abstract}

This article is an invited paper selected from abstracts submitted for the 2020 International Thermal Spray Conference, ITSC2020, that was to be held from June 10-12, 2020, in Vienna, Austria. The conference was cancelled due to the coronavirus (COVID-19) pandemic. The paper has been expanded from the planned presentation.

Maryam Yaghtin

myaghtin@mail.ubc.ca

1 Department of Materials Engineering, University of British Columbia, Vancouver, BC V6T 1Z4, Canada

2 Department of Materials Science and Engineering, College of Chemical and Metallurgical Engineering, Shiraz Branch, Islamic Azad University, 71993-1 Shiraz, Iran

3 Department of Materials Science and Engineering, School of Engineering, Shiraz University, 7134851154 Shiraz, Iran

4 Northwest Mettech Corp., Surrey, BC V4N 4C4, Canada of thermal barrier coatings (TBCs) with columnar morphology having porosity in the range of 17 to $18 \mathrm{vol} \%$.

Keywords columnar morphology · functional stability · surfactant $\cdot$ SPS coating $\cdot$ YSZ water-based suspension

\section{Introduction}

Thermal barrier coatings (TBCs) are widely applied on the metallic hot-section components of gas turbine engines to provide thermal and oxidation protection at high temperatures (Ref 1,2). The overall thermal efficiency and performance of these systems are strongly affected by the morphology and microstructural features of TBCs. Currently, the most widely used TBC material is $8 \mathrm{wt}$. \% yttriastabilized zirconia (8YSZ) which is normally deposited by electron beam-physical vapor deposition (EB-PVD) technique or atmospheric plasma spraying (APS). The conventional APS process results in the formation of coatings with lamellar microstructures and relatively low thermal conductivity $(\sim 1 \mathrm{~W} / \mathrm{mK})$ due to the presence of globular pores (Ref 3,4). Compared with the APS coatings possessing lamellar microstructures, EB-PVD coatings commonly have columnar-type microstructures. Consequently, EB-PVD coatings demonstrate higher strain tolerance and relatively higher thermal cycling life despite their higher thermal conductivity of 1.6-1.9 W/mK (Ref 1,5,6). The presence of dense columns as well as high inter-columnar spacing density ( $\sim 12$ cracks $/ \mathrm{mm}$ ) leads to higher thermal conductivity for coatings with columnar microstructure (Ref 7-9). Ideally, a TBC should have high strain tolerance to improve coating's lifetime, and sufficient amount $(>15$ vol.\%) of well-arranged, i.e., uniform and parallel to the 
substrate, fine porosity, to enhance coating's thermal insulation.

Suspension plasma spraying (SPS) allows direct injection of fine particles into the plasma jet which can lead to the formation of coatings with appropriate microstructure (i.e., having both strain tolerance and porosity features) and, therefore, acceptable thermal and lifetime properties (Ref 8,10). Ethanol-based suspension plasma-sprayed YSZ coatings can potentially have columnar-type microstructures which mimic the strain tolerant behavior of EB-PVD coatings (Ref 11). Consequently, SPS can be considered as a cost-effective alternative to EB-PVD by using an air plasma spray-based equipment (Ref 11). The SPS-TBCs usually have 15-20 vol.\% of porosity, comparable to those produced by the conventional APS method. Hence, the SPS coatings' microstructural features and cost advantages make it a promising technology for TBC production, particularly for the demanding gas turbine industry (Ref 12).

The microstructure and performance of SPS coatings are affected by both "suspension properties" such as surface tension, viscosity and density as well as "spraying parameters" including plasma power, enthalpy and spray distance (Ref 13,14). There is also a growing industrial demand to increase the coating deposition efficiency by feeding highly concentrated suspensions. In addition, replacing ethanol solvent with water would offer a more environmentally friendly process, reduce the manufacturing costs and enhance the process safety. The suspension characteristics, especially when water is used as the solvent, crucially influence the feasibility of formation of TBCs with porous columnar microstructures. This is the consequence of the fact that the slurry optimized rheological properties and stability affect the feedstock injection, increase its shelf life and improve the resulting coating's microstructure.

While the exact mechanism for column formation in SPS is still unknown, Van Every et. al. proposed a theory in this regard (Ref 15) which has been acknowledged by other researchers (Ref 13,16). Based on this theory, column formation in SPS greatly is affected by the suspension droplet formation after the suspension atomization inside plasma. This actually controls the formation of molten droplets of solute particles after solvent evaporation and solid melting. It has been reported that the trajectory of fine droplets, in the range of $1 \mu \mathrm{m}$ to $5 \mu \mathrm{m}$, can be strongly affected by plasma jet flow because of their low momentum (Ref 12). Therefore, these fine droplets can impact the surface at very shallow angles which with subsequent torch passes will result in shadowing effect at the surface asperities and end in a columnar type coating microstructure (Ref 12).

It has been reported that the atomized droplet size depends on a balance between the suspension properties that help it resist the fragmentation and the plasma shear forces that intend to break up the suspension stream into fine droplets (Ref 12,13). Suspension surface tension and viscosity are the main characteristics of the suspension which resist its break-up and droplet formation. The probability of pore formation in the microstructure of SPS coatings increases as the viscosity and surface tension of the utilized suspension decrease (Ref 13). Suspension rheological properties are controlled mainly by solvent type, solid content, surfactant type and concentration, $\mathrm{pH}$ and dispersants. Suspension preparation plays a significant role in SPS process because when water is used as the solvent, it is difficult to obtain a stable and well-dispersed suspension over time. Despite the intensive studies on SPS during the past decade, more research is required to address suspension preparation and its aging challenges in order to produce industrially scalable suspensions as SPS feedstocks.

In our previous study (Ref 17), we optimized the chemical composition of water-based YSZ suspensions for solid content, $\mathrm{pH}$ and surfactant (polyethyleneimine (PEI), 2-phosphonobutane-1,2,4-tricarboxylic acid (PBTCA) and $\alpha$-Terpineol) concentration to produce stable highly concentrated water-based YSZ suspensions. The functional stability of such highly concentrated ( $>20 \mathrm{wt} . \%)$ aqueous YSZ suspensions and their ability to produce TBCs with porous columnar microstructure are not known. The term "functional stability" refers to the ability of suspension to resist change in its rheological properties over aging time; it differs from "suspension stability" which is related to suspension resistance against particle agglomeration and subsequent sedimentation. The aim of the present study is to assess aging behavior of the optimized water-based YSZ suspensions with different types of surfactants and to investigate the microstructural characteristics of the resulting coatings that are deposited from such suspensions using the SPS method.

\section{Materials and Methods}

\section{Chemicals and Suspensions Preparation}

Yttria-stabilized zirconia (CrystalArc 8YSZ, with chemical composition of $\mathrm{ZrO}_{2}+\mathrm{HfO}_{2}=91.68$ wt. $\%$ and $\mathrm{Y}_{2} \mathrm{O}_{3}=7.95$ wt. $\%$ and particle size $\mathrm{D}_{50}$ value of $0.67 \mu \mathrm{m}$ ) was purchased from Northwest Mettech Cop., Surrey, BC, Canada, to prepare the water-based YSZ suspensions. Polyethyleneimine (PEI, Sigma-Aldrich, St. Louis, MO, USA), 2-phosphonobutane-1,2,4-tricarboxylic acid (PBTCA, TCI America, Portland, OR, USA) and Alpha-Terpineol, 96\% $(\alpha$-Terpineol, Thermo Fisher Scientific Chemicals Inc., Tewksbury, MA, USA) compounds were used as the 
surfactants (dispersants) to prepare three different waterbased YSZ suspensions of the chemical compositions presented in Table 1. The solid content, surfactant concentration and $\mathrm{pH}$ values attributed to each respective suspension were adjusted to their optimum values in accordance with the results in our previous study (Ref 17). Deionized water was used as the solvent for all the suspensions: S1-S4. In the preparation of each suspension, dispersant was first dissolved in $1 \mathrm{~L}$ deionized water following by gradual addition of $425 \mathrm{~g}$ YSZ powder under vigorous stirring. Dispersant concentration, mentioned as weight percent in Table 1 , is the ratio of the weight of the dispersant to the weight of YSZ powder in the suspension. Solutions of $0.1 \mathrm{~N}$ hydrochloric acid and ammonia were used to adjust suspension $\mathrm{pH}$ values in acidic and basic ranges, respectively. All the suspensions were continuously stirred for $24 \mathrm{~h}$ before setting to be aged over the time.

\section{Suspensions Characterization}

Rheological properties of the suspensions were investigated using MCR 502 rheometer (Anton Paar, Graz, Austria) with cup and bob geometry at room temperature. The reported viscosity values in Fig. $3 \mathrm{~b}$ have been measured at shear rate of $200 \mathrm{~s}^{-1}$ at which suspensions exhibited Newtonian behavior.

Zeta potential values attributed to different suspensions were obtained by NanoBrook Omni Zeta Potential Analyzer (Brookhaven, NY, USA). In order to measure the zeta potential values, a $0.1 \mathrm{mg} / \mathrm{ml}$ dilute aqueous sample of each suspension was prepared and then ultrasonicated for $60 \mathrm{~s}$. Sample's pH was adjusted by addition of $0.1 \mathrm{~N}$ hydrochloric acid or ammonia solution. Aggregate size values of different suspensions were estimated using MASTERSIZER 2000 (Malvern Instruments Ltd., Malvern, Worcestershire, UK). Similar pretreatment as that of zeta potential measurement experiments was used in order to measure aggregate sizes of different suspensions. The reported values are the average aggregate size attributed to each type of suspension. Surface tension values were measured using a Force Tensiometer (KRÜSS-K100 GmbH, Hamburg, Germany) device. All the measurements were made using Du Nouy Ring (Radius: $9.545 \mathrm{~mm} \&$ Wire Diameter: $0.37 \mathrm{~mm}$ ) lamella tear-off method. Turbiscan Lab Expert (Formulaction S.A., France), working with laser beam at wavelength of $880 \mathrm{~nm}$ and having two detectors for transmission and backscatter signals, was used to investigate the stability and sedimentation kinetics of the suspensions. Turbiscan Stability Index (TSI) values were calculated according to equation (1) (Ref 18):

$\mathrm{TSI}=\sqrt{\frac{\sum_{i=1}^{n}\left(x_{i}-x_{\mathrm{BS}}\right)^{2}}{n-1}}$

where $X_{i}$ is the mean backscattered light value for each time of measurement, $X_{\mathrm{BS}}$ is the average of $X_{i}$, and $n$ is the number of single scans during the total time of the experiment. Suspensions' ionic conductivity values were measured using a portable conductivity meter (Omega, Model CDH-5022, Karvina, Czech Republic) at room temperature.

We observed no significant changes in the suspensions' properties after aging time of 7 days. So, the practical aging time of one week (including one day intervals) was selected to assess the aging behavior of differently prepared suspensions. The variations in suspension zeta potential, $\mathrm{pH}$, viscosity and TSI values as a function of aging time were monitored over 7 days with measurement intervals of 1 day. Suspensions were aged at room temperature, in sealed plastic containers at still condition. During the aging time intervals, each suspension characterization method was the same as those stated above.

\section{Coatings Deposition and Characterization}

Inconel 718 sheet ( $2 \mathrm{~mm}$ thickness) was used as the substrate material. CoNiCrAlY powder (CO-210-24, Praxair Surface Technologies, Indianapolis, IN 46222, USA) was sprayed by Mettech Axial III (Northwest Mettech Corp., Surrey, Canada) APS system as the bond coat according to the experimental conditions presented in Table 2. Different suspensions, prepared based on our previous study (Ref 17) with chemical compositions shown in Table 1, were used to deposit the ceramic top coats using Mettech Axial III high power plasma torch equipped with a continuous stream suspension injector system (LP-BT100-2J Peristaltic pump including a YZII15 pump head with three rollers). The SPS processing parameters are summarized in Table 3. Morphologies of the resulting coatings were investigated with Zeiss Sigma standard field emission scanning electron
Table 1 Chemical composition of water-based $30 \mathrm{wt}$ \% YSZ suspensions.

\begin{tabular}{|c|c|c|c|c|}
\hline Suspension number & Dispersant type & Dispersant concentration, wt. $\%$ & Native $\mathrm{pH}$ & Adjusted $\mathrm{pH}$ \\
\hline S1 & $\ldots$ & $\ldots$ & 7.4 & 2.5 \\
\hline S2 & PEI & 0.1 & 9.1 & 2.5 \\
\hline S3 & PBTCA & 0.05 & 5.1 & 10.5 \\
\hline S4 & $\alpha$-Terpineol & 0.1 & 7.7 & 2.5 \\
\hline
\end{tabular}


Table 2 Atmospheric plasma spraying (APS) parameters utilized for bond coat deposition.

\begin{tabular}{ccccccc}
\hline $\begin{array}{c}\text { Powder feed } \\
\text { rate, g/min }\end{array}$ & Current, A & $\begin{array}{c}\text { Spray } \\
\text { distance, } \\
\mathrm{mm}\end{array}$ & $\begin{array}{c}\text { Total plasma gas flow } \\
\text { rate (SLM) }\end{array}$ & $\begin{array}{c}\text { Plasma gas composition } \\
\left(\mathrm{Ar} \% / \mathrm{N}_{2} \% / \mathrm{H}_{2} \%\right)\end{array}$ & $\begin{array}{c}\text { Total power during } \\
\text { spray, kW }\end{array}$ & $\begin{array}{c}\text { Nozzle internal } \\
\text { diameter, mm }\end{array}$ \\
\hline 90 & 230 & 200 & 250 & $70 / 10 / 20$ & 95 \\
\hline
\end{tabular}

Table 3 Suspension plasma spraying (SPS) parameters utilized for top coat deposition.

\begin{tabular}{|c|c|c|c|c|c|c|c|}
\hline $\begin{array}{l}\text { Suspension feed } \\
\text { rate, } \mathrm{mL} / \mathrm{min}\end{array}$ & $\begin{array}{c}\text { Current, } \\
\text { A }\end{array}$ & $\begin{array}{l}\text { Spray } \\
\text { distance, } \\
\text { mm }\end{array}$ & $\begin{array}{l}\text { Total plasma gas } \\
\text { flow rate (SLM) }\end{array}$ & $\begin{array}{c}\text { Plasma gas } \\
\text { composition }(\mathrm{Ar} \% / \\
\left.\mathrm{N}_{2} \% / \mathrm{H}_{2} \%\right)\end{array}$ & $\begin{array}{c}\text { Total power } \\
\text { during spray, } \\
\text { kW }\end{array}$ & $\begin{array}{l}\text { Atomizing gas } \\
\text { flow rate (SLM) }\end{array}$ & $\begin{array}{l}\text { Nozzle internal } \\
\text { diameter, mm }\end{array}$ \\
\hline 30 & 230 & 75 & 180 & $40 / 40 / 20$ & 98 & 25 & 9 \\
\hline
\end{tabular}

microscope. Porosity values in the microstructure of the resulting coatings were estimated by analyzing the respective SEM micrographs using image analyzer software (ImageJ-version 1.52a, National Institutes of Health, Maryland, USA).

\section{Results and Discussions}

\section{Zeta Potential and pH Measurements}

Figure 1a and c illustrates the variations in absolute zeta potential and $\mathrm{pH}$ values of the four different suspensions, listed in Table 1, as a function of aging time. It would be worthy to note that particles in blank suspension (as-prepared with only $\mathrm{pH}$ adjustment, undoped) and those including PEI and $\alpha$-Terpineol surfactants exhibit positive zeta potential values, while those in suspension including PBTCA surfactant exhibit negative zeta potential values at such experimental conditions. In fact, at fixed surfactant concentration, the main factor that influences the amount of zeta potential (making its absolute value high or low) is the deviation from point of zero charge (PZC). Based on the data presented in Fig. 1b (Ref 17), addition of $\alpha$-Terpineol surfactant to blank suspension results in a change in the value of PZC; so steric surfactants would also cause change in zeta potential values. Moreover, as can be seen, the zeta potential values attributed to the suspensions including $\alpha$ Terpineol surfactant do not change significantly as the $\mathrm{pH}$ changes in acidic region $(\mathrm{pH}<4)$. Actually, the high zeta potential values attributed to such suspensions are attributed to their adjusted $\mathrm{pH}$ values (2.5) which deviate from PZC pretty much.

As seen in Fig. 1, the zeta potential values decrease with the suspension aging time (Fig. 1a), and the suspension $\mathrm{pH}$ values change toward approaching the native $\mathrm{pH}$ values of the respective suspensions (Fig. 1c and Table 1). The native $\mathrm{pH}$ value corresponds to the $\mathrm{pH}$ value of each suspension observed immediately after preparation and prior to any further modifications. The change in zeta potential values over aging time could be related to the leaching of zirconium and yttrium ions into the solution, which in turn changes the characteristics of liquid medium and the double layer formed at the surface of suspended particles. Dissolution behavior of conventional micro-size zirconia particles has already been addressed appropriately (Ref 19,20). The YSZ powder that is used in the present study has average particle size of $0.67 \mu \mathrm{m}$ that makes it logical to consider such suspensions as those including sub-micron size particles $(<1 \mu \mathrm{m})$. Since the decrease in particle size usually leads to increase in thermodynamic driving force for dissolution process, it would not be surprising to expect YSZ dissolution in our experimental conditions like those which may be observed in nano-fluids. Time dependency of zeta potential has been reported previously for different suspension systems (Ref 21).

Another conclusion which would be made from data in Fig. 1 is that the blank suspension (S1) could be regarded as the most unstable one, i.e., having the highest percentage change in zeta potential value $(62 \%)$, which may be related to the enhanced solubility of YSZ in acidic medium as reported previously (Ref 22-24). In fact, dissolution of YSZ over the aging time would cause increase in suspensions conductivity values. Ionic conductivity measurements have shown that in the case of the suspensions under investigation, the conductivity increases over the aging time (almost from values less than $50 \mu \mathrm{S} / \mathrm{cm}$ for the fresh suspensions up to $700 \mu \mathrm{S} / \mathrm{cm}$ for the aged ones).

Application of surfactants leads to the formation of suspensions that are more functionally stable, i.e., exhibit 
Fig. 1 Variations in (a) zeta potential values versus aging time, b zeta potential values versus $\mathrm{pH}$ (Ref 17) and $\mathbf{c} \mathrm{pH}$ values as a function of aging time for different types of suspensions (S1-S4) (a)
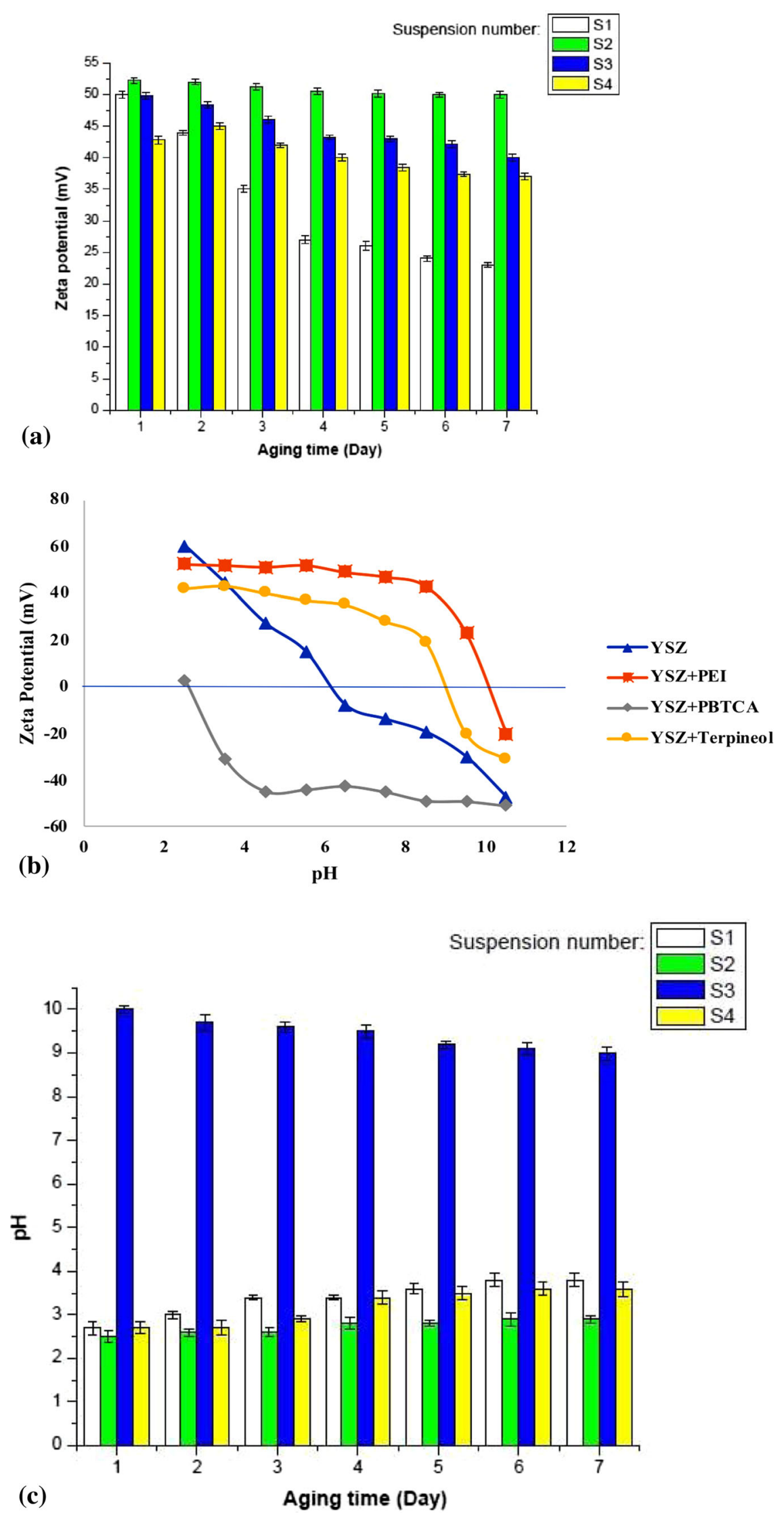
less changes in the zeta potential values because of aging. Although the $\mathrm{pH}$ change for the suspension with $\alpha$-Terpineol surfactant (S4) is comparable to that of the blank S1 (30\% and $34 \%$ for S4 and S1 suspensions, respectively), the zeta potential of the former does not change as significantly as in the case of the latter one (percentage change in zeta potential is about $11 \%$ in the case of suspension S4 which was aged for 7 days). This indicates that $\alpha$-Terpineol surfactant largely prevents changes in the suspension zeta potential as a result of changes in the suspension $\mathrm{pH}$ values. The stabilization mechanism that may be attributed to PEI and PBTCA surfactants would have both steric and electrostatic characters, while that of $\alpha$-Terpineol would be pure steric one. In the case of blank suspension (S1), stabilization mechanism is purely electrostatic which is sensitive to the ionic strength of the background liquid phase due to the screening effect on the repulsion forces between particles, i.e., the more ionic strength of the liquid phase, the less repulsive electrostatic forces between the charged particles would be. The increase in ionic strength would be the result of yttria leaching over the aging time that in turn leads to enhanced agglomeration in suspensions that are stabilized based on repulsive electrostatic forces as will be discussed later.

\section{Turbiscan Stability Index (TSI) Measurements}

The variation in TSI values of different suspensions as a function of aging time is presented in Fig. 2. The blank suspension (S1) can be considered as the most unstable one showing the highest TSI values. Increasing the aging time leads to an increase in TSI values, especially in the case of blank suspensions, indicating enhanced instability at longer aging times. Based on data shown in Figs. 1a and 2, PEI surfactant is the most efficient one to produce stable suspensions (i.e., ability to create the largest surface charge and as a result the least corresponding suspension TSI value). It would be related to its polycationic nature preventing particle agglomeration by simultaneous electrostatic and steric effects. The greater ability of PEI to produce stable suspensions (with respect to the two other surfactants) would also be related to its higher molecular weight providing effective steric repulsion forces in longer inter-particle distances. On the other hand, among different suspension systems studied here, the suspension including $\alpha$-Terpineol surfactant (S4) presents the least percentage change in the TSI value (32\%), indicating its ability to provide more functionally stable suspensions than the other types of surfactants. The average TSI values attributed to S2 and S4 suspensions are 8.3 and 10.3, respectively (i.e., $25 \%$ difference between their TSI values, approximately). On the other hand, the respective percentage changes in TSI values over the aging time are $57 \%$ and $32 \%$, in the case of S2 and S4 suspensions, respectively. In this regard, in spite of the fact that S2 suspension would be considered more stable than S4 suspension (by the factor of $25 \%$ ), it would be much less functionally stable than the former (approximately, 100\% difference between their respective

Fig. 2 TSI values as a function of aging time for different types

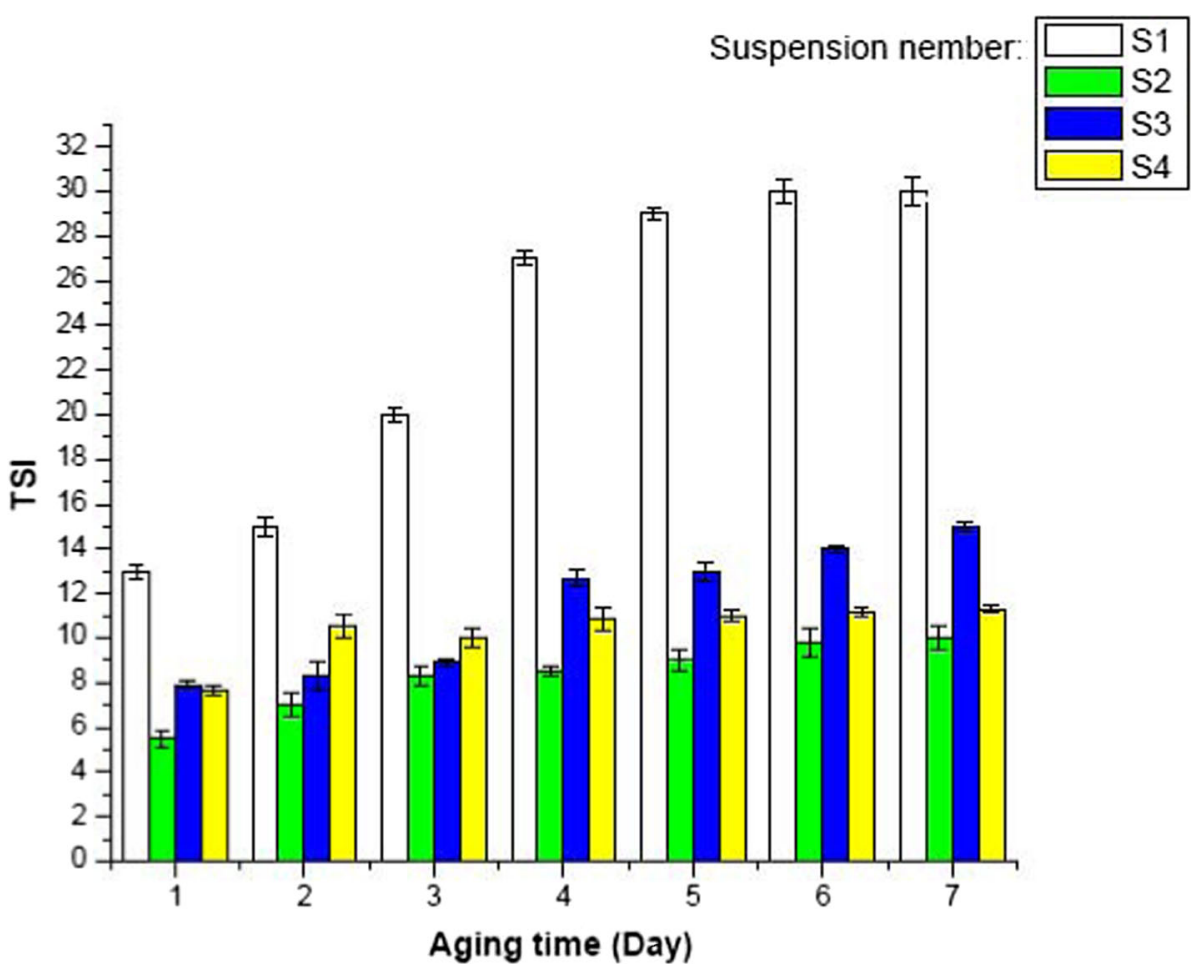


Fig. 3 a Typical suspensions' viscosity as a function of shear rate curves and $\mathbf{b}$ the

suspensions viscosity as a function of aging time for different types of suspensions (S1-S4)

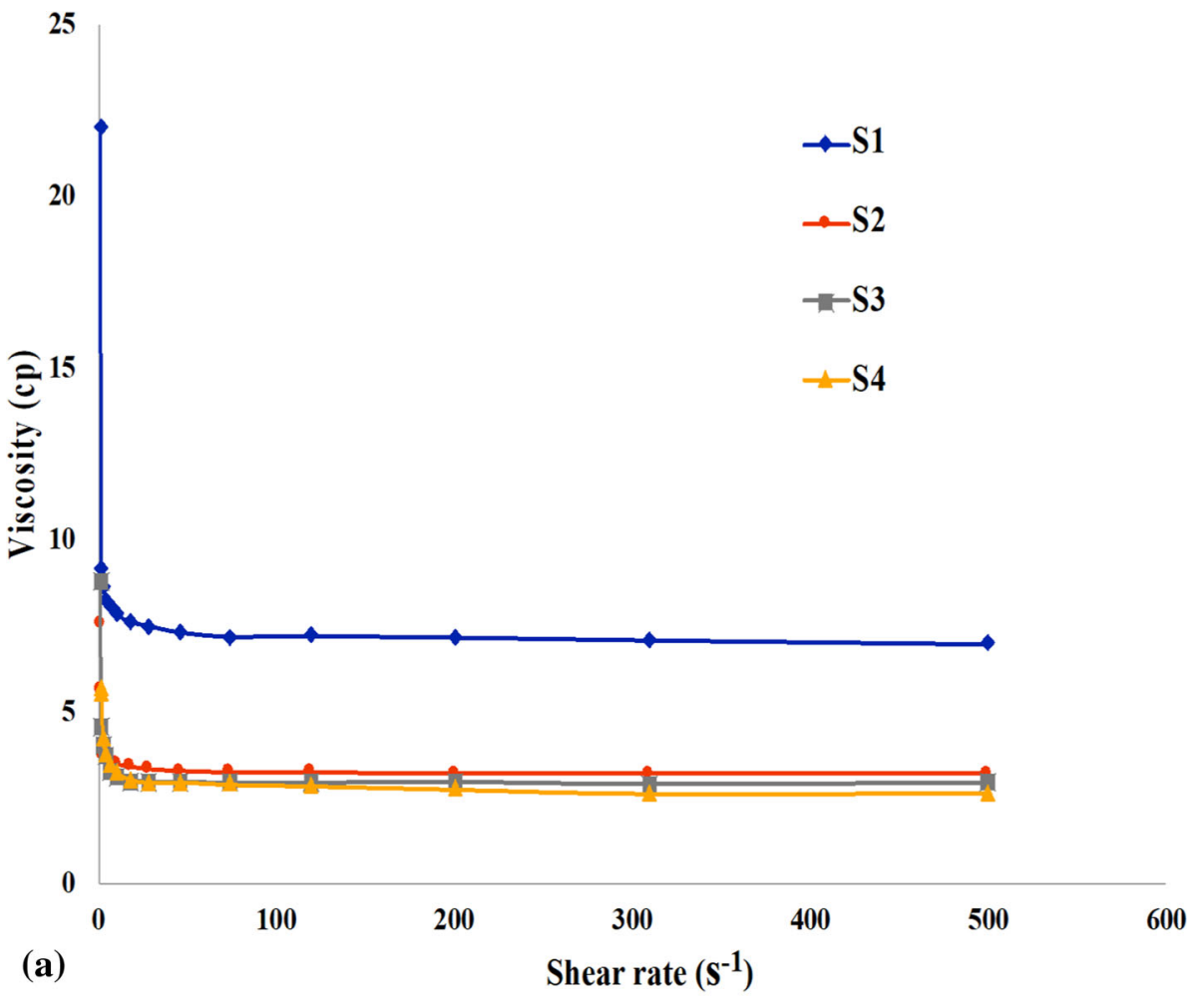

Suspension number:

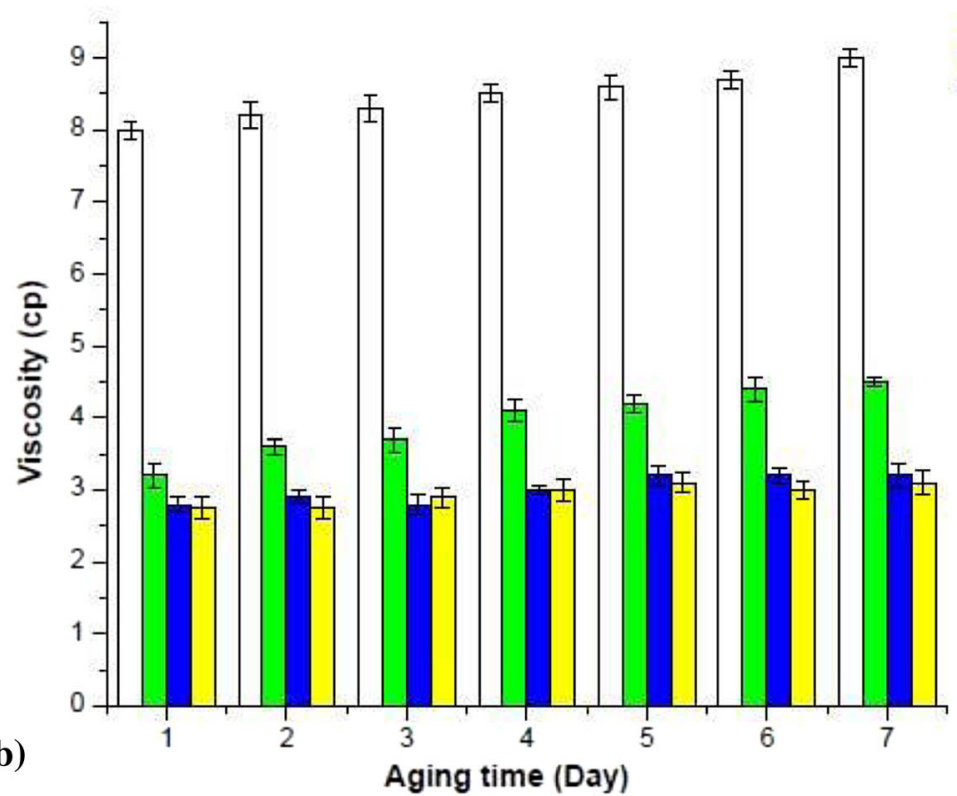

percentage changes in TSI values over the aging time). Such behavior could be related to the steric stabilization nature of $\alpha$-Terpineol surfactant that makes the resulting suspension characteristics less sensitive to $\mathrm{pH}$ changes (or change in liquid phase ionic strength) during the aging process (Ref 25).
Particle sedimentation would be affected by different factors namely as liquid phase viscosity and chance of particle agglomeration. The viscosity values of liquid phases attributed to different suspensions (S1-S4) are approximately the same (varying in the range of 1.4 to 1.7 $\mathrm{cp})$; it means that liquid phase viscosity effect on 


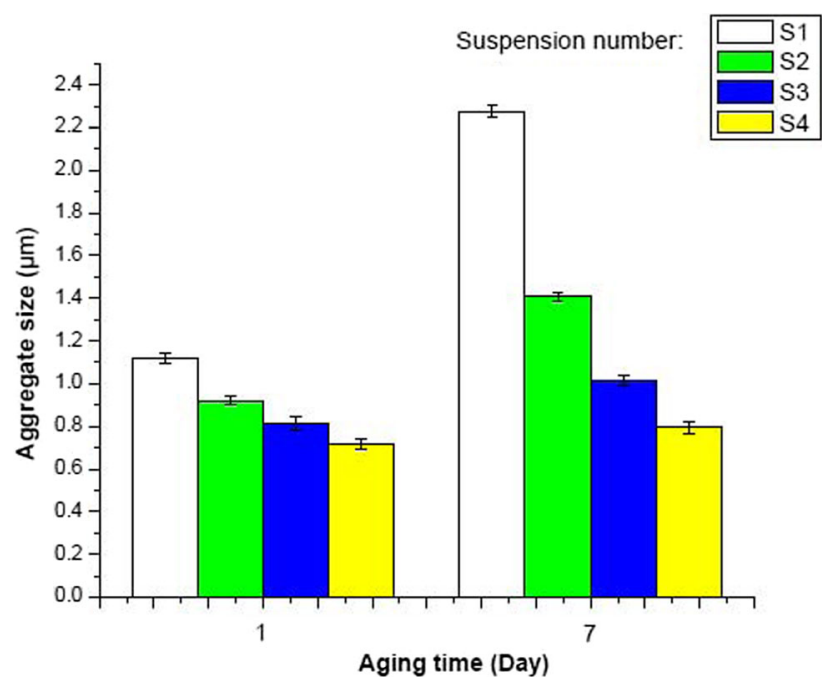

Fig. 4 The average aggregate size in different types of suspensions (S1-S4) as a function of aging time

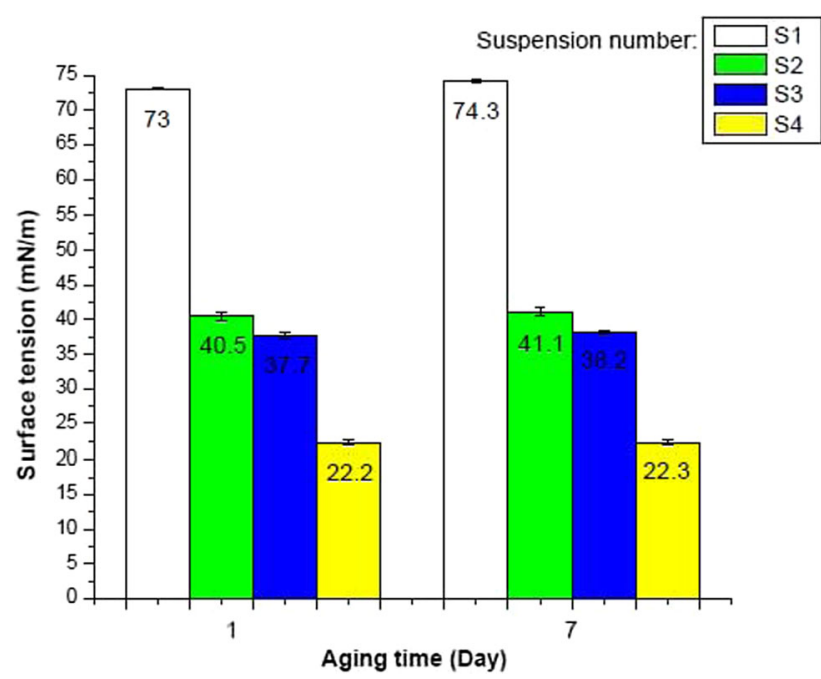

Fig. 5 Surface tension for different types of suspensions (S1-S4) as a function of aging time

sedimentation behavior is not significant. So, the chance of particle agglomeration would be regarded as the effective factor that may influence both the viscosity and sedimentation properties. Comparing the results showing the changes in TSI and viscosity values over the aging time (Figs. 2 and $3 \mathrm{~b}$ ) reveals that suspension aging leads to increase in the chance of particle agglomeration which in turn results in having suspensions with higher viscosity and less resistance to sedimentation.

\section{Suspensions Viscosity and Surface Tension Measurements}

Figure 3a shows the typical variation in suspensions' viscosity as a function of shear rate. As seen, all the suspensions exhibit shear thinning behavior and viscosity values almost remain constant at shear rates above $200 \mathrm{~s}^{-1}$. The variations in suspensions' viscosity values (at shear rate of $200 \mathrm{~s}^{-1}$ ) as a function of time are presented in Fig. 3b. As seen, blank suspension (S1) has the highest viscosity while adding different types of surfactants results in considerable decrease in suspension viscosities (values less than $50 \%$ of that of the blank suspension). Addition of surfactant types as PEI, PBTCA and $\alpha$-Terpineol results in the formation of suspensions with less viscosity values, respectively. The suspensions that were stabilized by $\alpha$ Terpineol surfactant (S4) exhibit the smallest viscosity. As can be seen in Fig. 4, $\alpha$-Terpineol surfactant is more likely to produce stable suspensions (i.e., with smaller aggregate sizes) than PEI and PBTCA surfactants, even after aging time of 7 days. It also indicates that for water-based YSZ suspensions, viscosity is directly affected by the colloidal aggregate size: the more the surfactant is efficient to reduce the aggregate size, the less the suspension viscosity would be. Dependence of suspension viscosity on the aggregate size has been also reported previously for other types of suspension systems (Ref 26,27). Another result from Fig. 3 is that the suspension viscosity increases as the aging time increases. The same trend was observed by Tarasi et al. in their study on viscosity variation of aged YSZ suspensions (Ref 26). The increase in suspension viscosity could be related to the re-agglomeration of suspended particles over time. Again, $\alpha$-Terpineol is the most effective surfactant type to produce functionally stable suspensions with the least percentage change in viscosity (10\%), which could be due to its steric stabilization mechanism discussed above.

Surface tension values attributed to different suspensions (S1-S4) are provided in Fig. 5. As seen, application of $\alpha$-Terpineol surfactant results in the formation of suspension with the least surface tension value. The significant difference between surface tension of the suspensions including different types of surfactants can be explained based on Gibbs adsorption isotherm (equation 2); in fact, the change in solution surface tension $(d \gamma)$ is related to the change in chemical potential of solution constituents $\left(d \mu_{i}\right)$ as follows:

$d \gamma=-\sum \Gamma_{i} d \mu_{i}$

where $\Gamma_{i}$ is the surface excess of solution constituent $i$. Based on equation (2), addition of surfactants which are less soluble in water (having higher surface excess) would result in the formation of solutions with less surface tension values. In this regard, the lower values of surface tension attributed to suspensions including $\alpha$-Terpineol surfactant would be related to its higher surface excess values in comparison with PEI and PBTCA surfactants (based on pure steric nature of the former that makes it less soluble in 
(a)
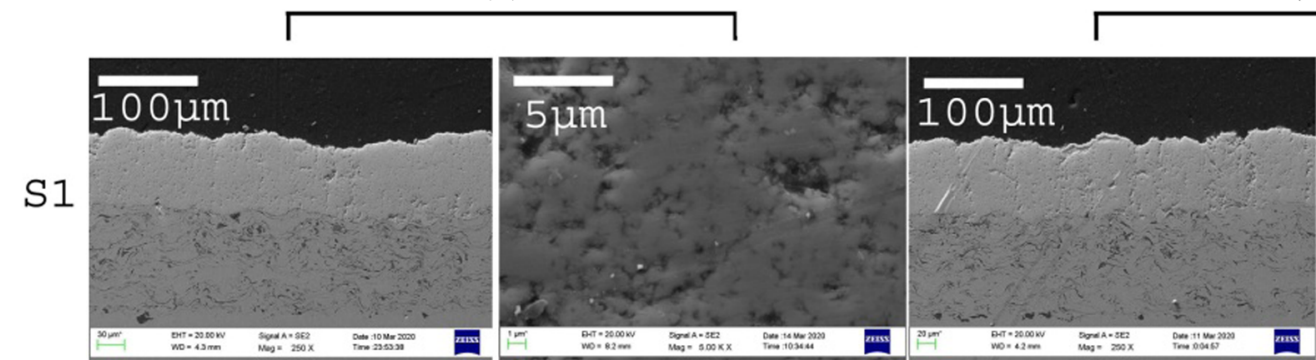

(b)
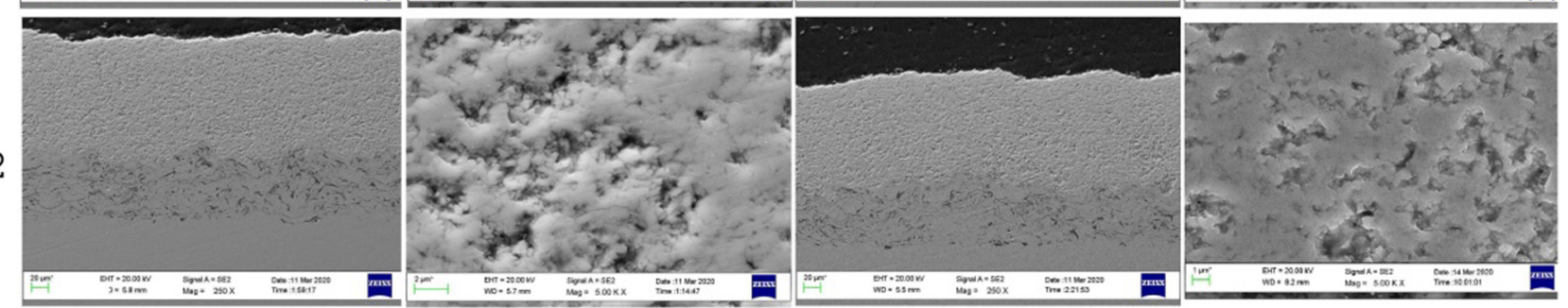

S3
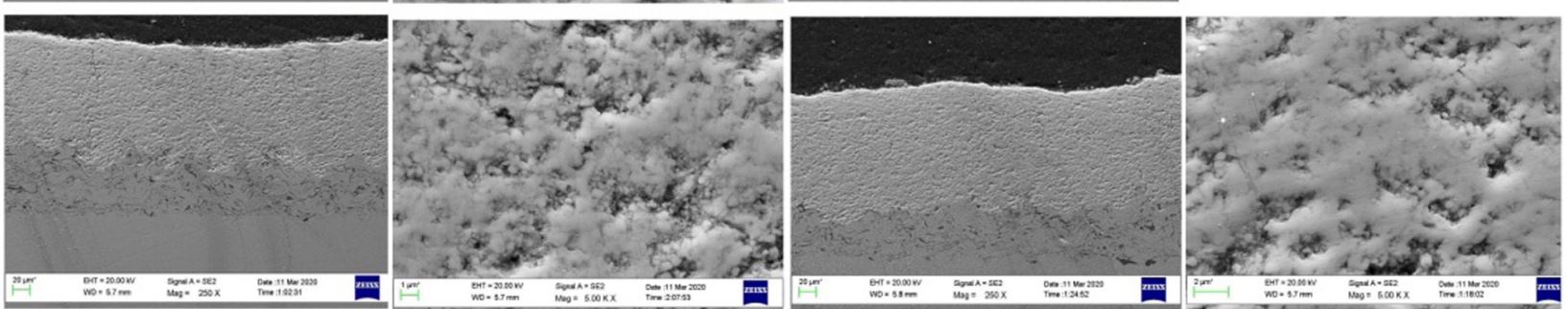

S4
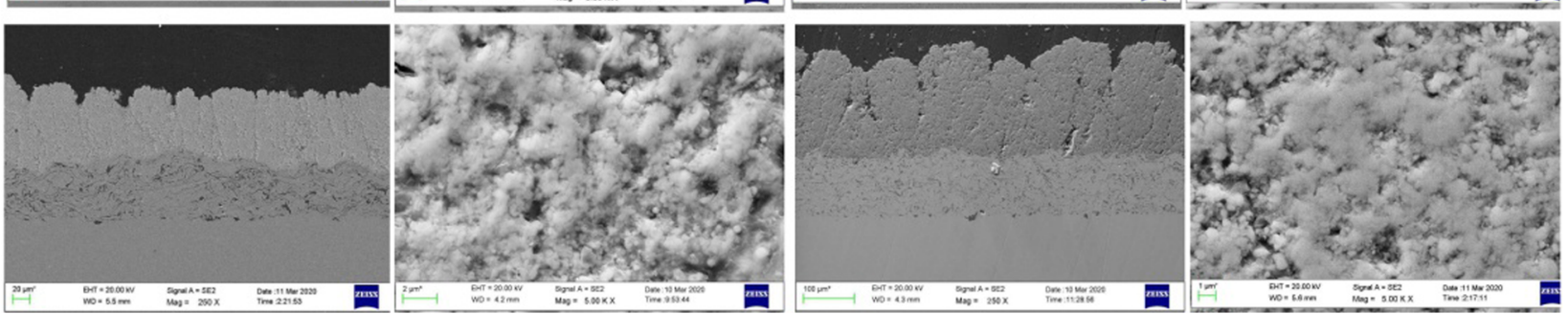

Fig. 6 The cross-sectional SEM images of coatings deposited from different types of suspensions (S1-S4) aged for (a) 1 day, and (b) 7 days. (Refer to text for the plasma spray deposition parameters)

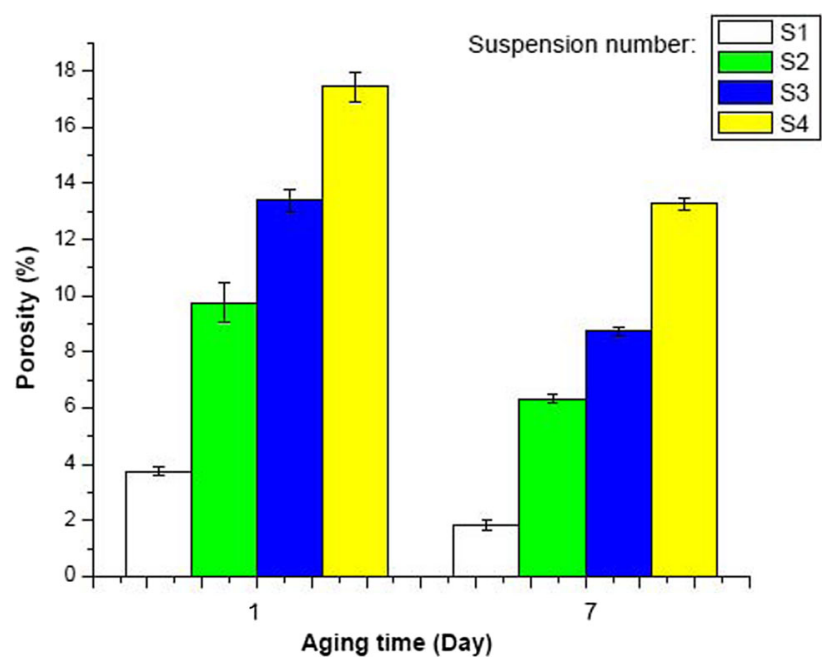

Fig. 7 Porosity values of the TBCs deposited from different suspensions (S1-S4) as a function of aging time water than the latter ones which have ionic character and are more soluble in water). Slight increase in surface tension of S4 is observed as the suspensions are aged for 7 days. Generally speaking, important factors that influence the suspension surface tension are solid content, particle interaction forces and surface tension of solvent liquid phase. Increase in solid content and inter-particle interaction results in increasing the suspension surface tension values. As a result, since the solid content of all the suspensions (S1-S4) is equal, the slight increase in surface tension values would be related to promoted inter-particle interaction over the aging time of the suspensions.

\section{Coatings' Morphology}

Figure 6 illustrates the SEM micrographs from the cross sections of SPS-YSZ coatings deposited from the four different types of suspensions listed in Table 1. Columnar 
microstructure can be observed for the coatings deposited from suspensions including $\alpha$-Terpineol surfactant (S4). It has been reported that spray droplet size significantly affects the final microstructure of the coatings. More specifically, the chance for the formation of columnar microstructure would be higher with smaller droplets, due to the so-called "shadowing effect" mechanism (Ref 12). At constant SPS deposition processing parameters, the two factors that resist suspension breakup and droplet formation are the viscosity and the surface tension of the suspension in such a way that suspensions with lower viscosity and surface tension values will be atomized to smaller droplets (Ref 13,14). The columnar structure in the morphology of coatings deposited from suspensions with $\alpha$-Terpineol surfactant (S4) could be, therefore, related to lower viscosity surface tension of such suspensions in comparison with the others (Figs. 3 and 5).

Porosity values attributed to the coatings deposited from different types of suspensions are presented in Fig. 7. The coatings' porosity decreases as they are deposited from suspensions including $\alpha$-Terpineol, PBTCA and PEI surfactants, respectively. As smaller droplets cool faster than the larger ones and have higher chance of treatment in the cooler plasma periphery region (since they may experience more influence from plasma drag at the substrate surface), the chance of molten droplet re-solidification (before impact to the substrate) increases as the droplet size decreases. The deposition of semi-molten droplets during SPS coating process has been also reported previously (Ref 13). Therefore, the most porous microstructure of the coatings deposited from the suspensions including $\alpha$-Terpineol surfactant could be related to the formation of smallest droplet size (due to their least viscosity and surface tension values) during the SPS process. As can be seen in Fig. 7, aging of different suspensions results in the formation of less porous coatings (in the case of all the suspensions S1-S4) and decrease the chance of columnar structure formation as in the case of suspension S4. As discussed above, it is obvious that regardless of the type of surfactant, aging of the suspensions would lead to increase in suspensions TSI and viscosity values. In other words, aging results in having suspensions which will be atomized to larger droplets in plasma plume. The large droplets will strike the substrate surface with much smaller trajectory than the small ones; it causes large splat formation at the point of droplet impact which in turn leads to the formation of dense coatings with less columnar character in their morphologies. In spite of the fact that suspension aging has led to the formation of less porous coatings (due to the increase in viscosity as a result of aging), the coatings deposited from suspensions including $\alpha$-Terpineol surfactant are still the ones with highest porosity values.

\section{Conclusions}

Functional stability of water-based 30 wt.\% YSZ suspensions including three types of surfactants (PEI, PBTCA and $\alpha$-Terpineol) was investigated. The results showed that both $\mathrm{pH}$ and zeta potential values attributed to different suspensions vary with the aging time as a result of YSZ powder dissolution over the time. These variations lead to increase in particle agglomeration tendency and subsequent changes in suspensions rheological properties. It was observed that $\alpha$-Terpineol surfactant produces the best functional stability for the suspensions (based on its pure steric characteristic) with the smallest change in the suspension viscosity and TSI values as a result of aging. In comparison with the coatings that were deposited from suspensions including PEI and PBTCA surfactants, the coatings that were deposited from $\alpha$-Terpineol containing suspensions exhibited columnar morphologies with higher porosity (17- $18 \mathrm{vol} . \%)$ than the others $(<14 \mathrm{vol} . \%)$ even after aging. Such coating morphologies are most likely related to the smallest viscosity and surface tension of the suspensions containing $\alpha$-Terpineol creating smaller droplets in plasma plume.

Acknowledgments The authors would like to acknowledge the financial support of the Natural Science and Engineering Research Council Canada, within "Green Surface Engineering for Advanced Manufacturing" (Green-SEAM) Strategic Network, for this work. We also express gratitude to Northwest Mettech Corporation for the collaboration in coatings deposition.

\section{References}

1. N.P. Padture, M. Gell and E.H. Jordan, Thermal barrier coatings for gas-turbine engine applications, Science (80-), 2002, 296(5566), p 280-284.

2. D.R. Clarke, M. Oechsner and N.P. Padture, Thermal-barrier coatings for more efficient gas-turbine engines, MRS Bull., 2012, 37(10), p 891-898.

3. P.L. Fauchais, J.V.R. Heberlein and M.I. Boulos, Thermal Spray Fundamentals: From Powder to Part, Springer, New York, 2014.

4. A. Ganvir, N. Curry, S. Govindarajan and N. Markocsan, Characterization of thermal barrier coatings produced by various thermal spray techniques using solid powder, suspension, and solution precursor feedstock material, Int. J. Appl. Ceram. Technol., 2016, 13(2), p 324-332.

5. T. Strangman, D. Raybould, A. Jameel and W. Baker, Damage mechanisms, life prediction, and development of EB-PVD thermal barrier coatings for turbine airfoils, Surf. Coat. Technol., 2007, 202, p 658-664.

6. H.J. Rätzer-Scheibe, U. Schulz and T. Krell, The effect of coating thickness on the thermal conductivity of EB-PVD PYSZ thermal barrier coatings, Surf. Coatings Technol., 2006, 200(18-19), p 5636-5644.

7. I.O. Golosnoy, A. Cipitria and T.W. Clyne, Heat transfer through plasma-sprayed thermal barrier coatings in gas turbines: a review of recent work, J. Therm. Spray Technol., 2009, 18(5-6), p 809821. 
8. A. Ganvir, N. Curry, S. Björklund, N. Markocsan and P. Nylén, Characterization of microstructure and thermal properties of YSZ coatings obtained by axial suspension plasma spraying (ASPS), $J$. Therm. Spray Technol., 2015, 24(7), p 1195-1204.

9. B. Bernard, A. Quet, L. Bianchi and B. Remy, Thermal insulation properties of YSZ coatings: suspension plasma spraying (SPS) versus electron beam physical vapor deposition (EB-PVD) and atmospheric plasma spraying (APS), Surf. Coat. Technol., 2017, 318, p 122-128.

10. A. Ganvir, N. Curry, N. Markocsan, P. Nylén, S. Joshi, M. Vilemova and Z. Pala, Influence of microstructure on thermal properties of axial suspension plasma-sprayed YSZ thermal barrier coatings, J. Therm. Spray Technol., 2015, 25(1-2), p 202-212.

11. A. Feuerstein, J. Knapp, T. Taylor, A. Ashary, A. Bolcavage and N. Hitchman, Technical and economical aspects of current thermal barrier coating systems for gas turbine engines by thermal spray and EB-PVD: a review, J. Therm. Spray Technol., 2008, 17, p 199-213.

12. A. Ganvir, R.F. Calinas, N. Markocsan, N. Curry and S. Joshi, Experimental visualization of microstructure evolution during suspension plasma spraying of thermal barrier coatings, 2, Elsevier, 2019, 39(2-3), p 470-481.

13. N. Curry, K. VanEvery, T. Snyder, J. Susnjar and S. Bjorklund, Performance testing of suspension plasma sprayed thermal barrier coatings produced with varied suspension parameters, Coatings, 2015, 5(3), p 338-356.

14. R. Rampon, O. Marchand, C. Filiatre and G. Bertrand, Influence of suspension characteristics on coatings microstructure obtained by suspension plasma spraying, Surf. Coatings Technol., 2008, 202, p 4337-4342.

15. K. Vanevery, M.J.M. Krane, R.W. Trice, H. Wang, W. Porter, M. Besser, D. Sordelet, J. Ilavsky and J. Almer, Column formation in suspension plasma-sprayed coatings and resultant thermal properties, J. Therm. Spray Technol., 2011, 20(4), p 817-828.

16. P. Sokołowski, L. Pawłowski, D. Dietrich, T. Lampke and D. Jech, Advanced microscopic study of suspension plasma-sprayed zirconia coatings with different microstructures, J. Therm. Spray Technol., 2015, 25(1-2), p 94-104.

17. M. Yaghtin, A.H. Yaghtin, Z. Tang and T. Troczynski, Improving the rheological and stability characteristics of highly concentrated aqueous yttria stabilized zirconia slurries, Ceram. Int., 2020, 46(17), p 26991-26999.

18. M. Wiśniewska, S. Chibowski and T. Urban, Adsorption of cationic polyacrylamide on the surface of mesoporous nanozirconia and its influence on the solid aqueous suspension stability, Colloids Surf. A Physicochem. Eng. Asp., 2016, 509, p 214-223.

19. W.B. Blumenthal, The Chemical Behavior of Zirconium, New York (etc.), 1958.

20. T. Takeuchi and K. Kawamura, Effect of the crystal structure on the acid dissolution of zirconium oxide, Trans. Jpn. Inst. Met., 1972, 13(4), p 262-264.

21. I.M. Mahbubul, Preparation, Characterization Properties and Application of Nanofluid, Elsevier, Amsterdam, 2019.

22. E. Curti and C. Degueldre, Solubility and hydrolysis of $\mathrm{Zr}$ oxides: a review and supplemental data, Radiochim. Acta, 2002, 90(911), p 801-804.

23. S.N. Lvov, X.Y. Zhou, G.C. Ulmer, H.L. Barnes, D.D. Macdonald, S.M. Ulyanov, L.G. Benning, D.E. Grandstaff, M. Manna and E. Vicenzi, Progress on yttria-stabilized zirconia sensors for hydrothermal PH measurements, Chem. Geol., 2003, 198, p 141162.

24. T. Kobayashi, T. Sasaki, I. Takagi and H. Moriyama, Solubility of zirconium ( IV ) hydrous oxides, J. Nucl. Sci. Technol., 2007, 44(1), p 90-94.

25. L. Chong, Y. Lai, M. Gray, Y. Soong, F. Shi and Y. Duan, Molecular dynamics study of the bulk and interface properties of frother and oil with saltwater and air, J. Phys. Chem. B, 2017, 121(13), p 2788-2796.

26. T. Gillespie, The effect of aggregation and particle size distribution on the viscosity of newtonian suspensions, J. Colloid Interface Sci., 1982, 94(1), p 166-173.

27. E. Behzadfar, M.H. Abdolrasouli, F. Sharif and H. Nazockdast, Effect of solid loading and aggregate size on the rheological behavior of pdms/calcium carbonate suspensions, Braz. J. Chem. Eng., 2009, 26(4), p 713-721.

Publisher's Note Springer Nature remains neutral with regard to jurisdictional claims in published maps and institutional affiliations. 